\title{
Prognostic Factors for Open Globe Injuries and Correlation of Ocular Trauma Score in Tianjin, China
}

\author{
Yu Meng and Hua Yan \\ Department of Ophthalmology, Tianjin Medical University General Hospital, No. 154, Anshan Road, Tianjin 300052, China \\ Correspondence should be addressed to Hua Yan; phuayan2000@163.com
}

Received 27 July 2015; Revised 1 September 2015; Accepted 14 September 2015

Academic Editor: Tamer A. Macky

Copyright ( 2015 Y. Meng and H. Yan. This is an open access article distributed under the Creative Commons Attribution License, which permits unrestricted use, distribution, and reproduction in any medium, provided the original work is properly cited.

\begin{abstract}
Purpose. To investigate prognostic factors that influence the final visual acuity (VA) and to correlate the ocular trauma score (OTS) with the final VA in open globe injuries. Methods. A retrospective review of 298 patients with open globe injuries admitted to Tianjin Medical University General Hospital was carried out from January 1, 2010, till December 31, 2014. Prognostic factors influencing the final VA in patients with open globe injuries and the correlation between OTS and the final VA were examined. Results. Three hundred and fourteen eyes from 298 patients with open globe injuries were analyzed. Males had a higher rate of open globe injury than females ( $83.56 \%$ versus $16.44 \%$ ). Mean age was $45.46 \pm 17.48$ years (5-95 years). In a univariate analysis, prognostic factors influencing the final VA included initial VA, relative afferent papillary defect (RAPD), vitreous hemorrhage, lens injury, endophthalmitis, hyphema, retinal detachment, and the zone of injury. In a multiple logistic regression analysis, initial VA, RAPD, and the zone of injury were considered to be independent risk factors. The OTS correlated with final VA $(r=0.988, p=0.000)$. Conclusion. In our study, the most important prognostic factors influencing the final VA were initial VA, RAPD, and the zone of injury. The OTS was of great importance for patients and ophthalmologists.
\end{abstract}

\section{Introduction}

Open globe injury, defined as a full thickness wound of the eye wall [1], is a major but preventable cause of permanent visual impairment and blindness in the world [2]. The World Health Organization program estimated that approximately 750,000 cases of ocular trauma are hospitalized per year, and 200,000 cases are open globe injuries worldwide [3].

Despite advances in ophthalmic surgery such as operating microscopes, vitreoretinal techniques, and surgical skills together with improvements in the awareness of visual prognosis, instrumentations, and other factors that have led to better outcomes, there remain a number of eyes that cannot be salvaged [4]. They impact not only the individuals, but also the country's healthcare system [5].

Based on literature review, factors likely to predict the final visual acuity (VA) after open globe injury are initial VA, mechanism or type of injury, zone of injury, adnexal trauma, relative afferent pupillary defect (RAPD), retinal detachment, uveal or retinal tissue prolapse, vitreous hemorrhage, lens injury, hyphema, delay to surgery, and number of operative procedures [6-24]. One of the most important uses of knowing about prognostic factors is that it helps the physician in counselling the patient and his family and preparing him for the outcome.

Ocular trauma score (OTS) system suggested by Kuhn et al. [25] is to predict the final VA after an open globe injury. Kuhn et al. [25] analyzed more than 2500 injured eyes from the United States and Hungarian Eye Injury Registries (USEIR) and evaluated more than 100 variables with the goal of identifying specific predictors. OTS is calculated by assigning definite numerical raw points to six variables: initial VA, rupture, endophthalmitis, perforating injury, retinal detachment, and RAPD (Table 1). The scores are stratified into five categories that give the predictabilities of final VA.

Little data is currently available on open globe injury in Tianjin. The aims of this study were to determine prognostic factors influencing the final VA and to validate the OTS in patients with open globe injuries. 
TABLE 1: Calculating the ocular trauma score (OTS): variables and raw points.

\begin{tabular}{lc}
\hline Variables & Raw points \\
\hline Initial VA & \\
NLP & 60 \\
LP/HM & 70 \\
$1 / 200-19 / 200$ & 80 \\
$20 / 200-20 / 50$ & 90 \\
$\geq 20 / 40$ & 100 \\
Rupture & -23 \\
Endophthalmitis & -17 \\
Perforating injury & -14 \\
Retinal detachment & -11 \\
RAPD & -10 \\
\hline
\end{tabular}

\section{Methods}

A retrospective review of medical records of all consecutive patients with open globe injuries from January 1, 2010, till December 31, 2014, at Tianjin Medical University General Hospital was carried out.

Case notes were examined to determine demographic data (age and gender), eye(s) involved, cause and place of injury, and type of injury. Initial VA, zone of injury, and clinical signs (hyphema, lens injury, RAPD, endophthalmitis, retinal detachment, and vitreous hemorrhage) were recorded. Management, follow-up data, duration of hospitalization, injury time (from the point of injury to presentation at the clinic), and final VA were also documented. We also utilized the OTS to evaluate the final VA.

Type of injury was based on the Ocular Trauma Classification Group: rupture, penetrating injury, intraocular foreign body, or perforating injury [1]. Zone of injury was defined according to the Ocular Trauma Classification Group: zone 1 (the whole cornea, including corneoscleral limbus), zone 2 (corneoscleral limbus to a point $5 \mathrm{~mm}$ posterior into the sclera), and zone 3 (posterior to the anterior $5 \mathrm{~mm}$ of the sclera) [1].

Initial and final VAs were classified as no light perception (NLP) and light perception (LP)/hand motion (HM), 1/200$19 / 200,20 / 200-20 / 50$, and $\geq 20 / 40$. A good visual outcome was defined as a final VA of 20/200 or better, while a poor visual outcome was defined as a final VA of less than 20/200.

Patients with previous ocular surgery and preexisting ocular conditions affecting VA as well as those with less than 6 months of follow-up were excluded.

Statistical analysis was carried out using SPSS version 19.0 statistical software (IBM, Armonk, NY, USA). Data was expressed as the mean \pm SD (Standard Deviation) for continuous variables. Univariate logistic regression analysis was used to examine the association between prognostic factors (type of injury, initial VA, zone of injury, and clinical signs) and the final VA. Furthermore, all the factors found significant in univariate logistic analysis were included in the multivariate analysis. The odds ratio (OR) and 95\%
TABLE 2: Characteristics of patients with open globe injuries.

\begin{tabular}{lc}
\hline Variables & $n$ \\
\hline Total patients (total injured eyes) & $298(314)$ \\
Female/male & $49 / 249$ \\
Age (years, mean $\pm \mathrm{SD}^{\mathrm{a}}$ ) & $45.46 \pm 17.48$ \\
Right/left/both & $135 / 147 / 16$ \\
Mean duration of hospitalization (days) & $15.01 \pm 11.73$ \\
Injury time (hours) & \\
0-24 & 200 \\
$\geq 24$ & 98 \\
Places of injuries & \\
Workplace & 149 \\
Home & 77 \\
School & 4 \\
Road & 56 \\
Others & 12 \\
Cause of injuries & \\
Metallic objects & 153 \\
Traffic accidents & 56 \\
Falling & 44 \\
Blunt objects & 28 \\
Others & 17 \\
Diagnosis & \\
Penetrating injury & 172 \\
Intraocular foreign body & \\
Perforating injury & \\
Rupture & \\
\hline
\end{tabular}

${ }^{\mathrm{a}} \mathrm{SD}$ : standard deviation.

confidence interval (CI) for variables were calculated as well. A $p$ value of 0.05 was considered statistically significant.

\section{Results}

This current study included data from 314 eyes from 298 patients over a 5-year period. Two hundred and forty-nine (83.56\%) patients were males and 49 (16.44\%) patients were females. Mean age was $45.46 \pm 17.48$ years (5-95 years). One hundred and sixty-five $(55.03 \%)$ patients occurred in aged 21-50-year-old group. Right eyes were associated with 135 (45.30\%) patients and left eyes with 147 (49.33\%) patients. Sixteen $(5.4 \%)$ patients had bilateral eyes involvement. Mean duration of hospitalization was $15.01 \pm 11.73$ days (2-68 days). Two hundred (69.46\%) patients took less than 24 hours to look for medical care after their injuries; however, 9 (14.9\%) patients still took more than 4 days. Mean duration of followup was $8.40 \pm 2.30$ months (6.10-10.70 months). One hundred and forty-nine $(50.00 \%)$ injuries happened in the workplace, $77(25.84 \%)$ happened at home, and $53(17.78 \%)$ on the road. Most of the injuries were caused by metallic objects (153, $51.34 \%$ ) followed by traffic accidents $(56,18.79 \%)$ (Table 2 ).

Regarding type of injury, penetrating injury (192, 61.15\%) accounted for the majority of open globe injuries, followed by intraocular foreign body $(83,26.43 \%)$. Rupture $(17,5.41 \%)$ 
TABLE 3: Univariate logistic regression analysis of factors which affected final visual acuity.

\begin{tabular}{|c|c|c|c|}
\hline \multirow{2}{*}{ Variables } & \multicolumn{2}{|c|}{ Final VA } & \multirow{2}{*}{$p$} \\
\hline & $\geq 20 / 200$ & $<20 / 200$ & \\
\hline Type of injury & & & 0.8000 \\
\hline Penetrating injury & 76 & 116 & \\
\hline Perforating injury & 15 & 7 & \\
\hline Intraocular foreign body & 26 & 57 & \\
\hline Rupture & 5 & 12 & \\
\hline Initial VA & & & 0.000 \\
\hline$\geq 20 / 200$ & 61 & 185 & \\
\hline$<20 / 200$ & 61 & 7 & \\
\hline RAPD & & & 0.002 \\
\hline No & 114 & 153 & \\
\hline Yes & 8 & 39 & \\
\hline Retinal detachment & & & 0.002 \\
\hline No & 119 & 163 & \\
\hline Yes & 3 & 29 & \\
\hline Vitreous hemorrhage & & & 0.000 \\
\hline No & 102 & 100 & \\
\hline Yes & 20 & 92 & \\
\hline Hyphema & & & 0.000 \\
\hline No & 57 & 42 & \\
\hline Yes & 65 & 150 & \\
\hline Lens injury & & & 0.000 \\
\hline No & 102 & 200 & \\
\hline Yes & 40 & 72 & \\
\hline Endophthalmitis & & & 0.014 \\
\hline No & 115 & 163 & \\
\hline Yes & 7 & 29 & \\
\hline Zone of injury & & & 0.000 \\
\hline 1 & 90 & 80 & \\
\hline 2 & 32 & 52 & \\
\hline 3 & 0 & 60 & \\
\hline
\end{tabular}

and perforating injury $(22,7.01 \%)$ accounted for the remaining open globe injuries. Of the 22 perforating injury eyes, $7(31.82 \%)$ eyes had final VA of less than 20/200, and 15 (68.18\%) eyes had final VA of 20/200 or better. All patients received intravitreal and systemic antibiotics. Two hundred (90.40\%) eyes underwent one surgical procedure, 94 (29.91\%) eyes underwent two surgical procedures, and $20(6.40 \%)$ eyes underwent three or more surgical procedures (Table 2).

In terms of the zone of injury, 170 (54.14\%) eyes had zone 1 injuries, 84 (26.75\%) eyes had zone 2 injuries, and 60 (19.11\%) eyes had zone 3 injuries. Hyphema was associated with 215 (68.47\%) eyes and vitreous hemorrhage was associated with 112 (35.67\%) eyes. Lens injury was found in 112 (35.67\%) eyes. RAPD was noted in 47 eyes (14.97\%). Endophthalmitis was present in 36 eyes (11.46\%). Retinal detachment was observed in $32(10.19 \%)$ eyes (Table 3$)$.

The distribution of initial and final VA was illustrated in Figure 1. Twelve (3.8\%) eyes had initial VA of $20 / 40$ or better, 56 (17.8\%) eyes had initial VA of 20/200-20/50, 69

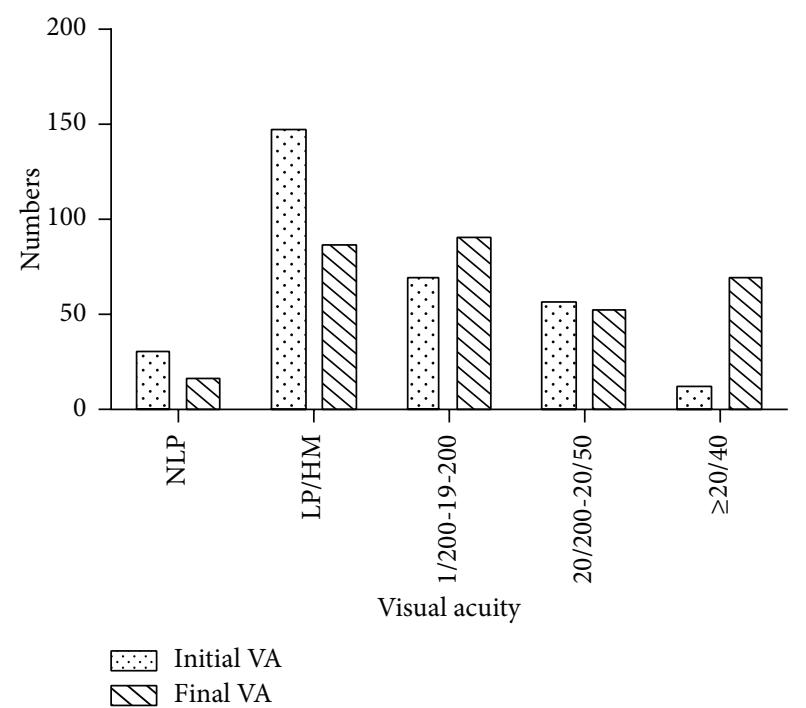

Figure 1

TABLE 4: Multiple logistic regression analysis of factors which mostly affected final visual acuity.

\begin{tabular}{lccc}
\hline Variables & $p$ & OR & $95 \%$ CI \\
\hline Initial VA & 0.000 & 8.329 & $3.310-20.959$ \\
RAPD & 0.023 & 4.788 & $1.241-18.478$ \\
Zone of injury & 0.000 & 2.709 & $1.577-4.653$ \\
\hline
\end{tabular}

(22.0\%) eyes had initial VA of 1/200-19/200, 147 (46.8\%) eyes had initial VA of LP/HM, and the remaining 30 (9.6\%) eyes had initial VA of NLP. After about 6 months follow-up, 70 (22.29\%) eyes had VA of 20/40 or better, 52 (16.57\%) eyes had final VA of 20/200-20/50, 90 (28.66\%) had final VA of $1 / 200-19 / 200,86(27.39 \%)$ had final VA of LP/HM, and the remaining $16(5.10 \%)$ eyes had final VA of NLP.

Based on the univariate logistic regression analysis, prognostic factors such as initial VA $(p=0.000)$, RAPD ( $p=$ $0.002)$, retinal detachment $(p=0.002)$, vitreous hemorrhage $(p=0.000)$, hyphema $(p=0.000)$, lens injury $(p=0.000)$, endophthalmitis $(p=0.014)$, and zone of injury $(p=0.000)$ adversely affected the final VA (Table 3 ).

All factors found significant in univariate logistic analysis were included in the multivariate logistic analysis to further evaluate their associations with final VA. Initial VA $(p=$ $0.000, \mathrm{OR}=8.329,95 \% \mathrm{CI}=3.310-20.959), \mathrm{RAPD}(p=0.023$, $\mathrm{OR}=4.788,95 \% \mathrm{CI}=1.241-18.478)$, and the zone of injury $(p=0.000, \mathrm{OR}=2.709,95 \% \mathrm{CI}=1.577-4.653)$ were found to be the most statistically significant for the final VA (Table 4).

Three hundred and fourteen eyes were classified within OTS categories one through five. Against USEIR-OTS system, our study had a smaller sample size; we still could see close resemblance between the scores in our study and that in USEIR study of OTS. The OTS correlated with final VA $(r=$ $0.988, p=0.000$ ) (Table 5). 
TABle 5: Percentage with final VA and OTS categorical distribution in this study and the OTS study.

\begin{tabular}{lcccccc}
\hline Raw OTS & OTS & NLP & LP/HM & $1 / 200-20 / 200$ & $20 / 200-20 / 50$ & $\geq 20 / 40$ \\
\hline $0-44$ & 1 & $30 / 74$ & $53 / 15$ & $17 / 7$ & $51 / 18$ & $3 / 15$ \\
$45-65$ & 2 & $0 / 27$ & $46 / 26$ & $17 / 15$ & $38 / 31$ & $0 / 15$ \\
$66-80$ & 3 & $0 / 2$ & $0 / 11$ & $0 / 3$ & $44 / 22$ & $0 / 5$ \\
$81-91$ & 4 & $0 / 1$ & $0 / 2$ & $0 / 1$ & $56 / 73$ \\
$92-100$ & 5 & $0 / 0$ & $0 / 1$ & & $100 / 94$ \\
\hline
\end{tabular}

This study/OTS study.

\section{Discussion}

We found that open globe injuries occurred predominantly in males, consistent with other studies $[13,26]$. This might be due to gender-based behavior and male involvement in higher risk of working activities. Mean age in our study was $45.46 \pm 17.48$ years and most of the injuries occurred in groups aged 21-50 which were similar to other studies [13, 27]. Most of the patients $(50.00 \%)$ occurred in the workplace. Better education of workers as regards workplace safety and the provision and use of protective eye wear will help reduce the incidence of open globe injury in the workplace. Majority of the patients $(69.46 \%)$ could seek for medical care timely. However, nine (14.9\%) patients still took more than 4 days, and all of them ended up with final VA of less than 20/200, 6 cases with a result of final VA of LP/HM, and 3 cases with a result of final VA of 1/200-19/200. Poverty and a lack of awareness might hamper timely management of ocular injuries.

In our study, of the 30 eyes with initial VA of NLP, 14 eyes ended with improved vision, and the remaining 16 eyes still had VA of NLP at last follow-up. Among the 14 eyes that ended with improved vision, only 1 eye regained useful ambulatory vision; the remaining 13 eyes achieved final VA of less than 20/200. For the 16 eyes with final VA of NLP, 4 eyes were as a result of primary enucleation, 6 eyes were as a result of secondary enucleation, and 6 eyes were as a result of phthisis bulbi. Schmidt et al. [22] have demonstrated that initial VA was found to correlate significantly with the final VA in open globe injuries. Our study showed similar results that patients who had initial VA of 20/200 or better had improvement in final VA; however, majority of patients with initial VA of LP/HM or worse had poor final VA. Based on multivariate logistic regression analysis, initial VA had statistically significant influence on the final VA $(p<0.001)$.

Pieramici et al. [19] found that if RAPD was present, final VA was significantly worse. In our study, 39 patients had final VA of less than 20/200 if RAPD was present; using multivariate logistic regression analysis, presence of RAPD had statistically significant influence on the final VA $(p=0.023)$. However, it was a concern that there was a tendency not to examine the pupil responses during the initial examination of open globe injuries, so examining for a reverse afferent should be instructed as an essential part.

Retinal detachment, induced by direct trauma or traction of proliferative vitreous in open globe injuries, was found to be a significant prognostic factor by Hutton and Fuller [28] and Thompson et al. [29]. When it occurs, photoreceptor cells are probably seriously injured and may lead to limited final VA. In our study, 29 (90.63\%) patients with retinal detachment had poor final VA of less than 20/200, confirming its importance as a prognostic factor $(p<0.001)$ by multivariate logistic regression analysis.

Vitreous hemorrhage, caused by rupture of blood vessels in the ciliary body, retina, urea, or sclera, was found to be a prognostic factor [30]. When it occurs, it may be related to serious damage of eye tissues. In our study, 92 (60.92\%) patients with vitreous hemorrhage had final VAs that were less than 20/200. Using univariate logistic regression analysis, presence of vitreous hemorrhage had statistically significant influence on the final VA $(p=0.000)$.

Hyphema also played a role in final VA [31]. Madhusudhan et al. [26] found that patients who did not have hyphema were twice less likely to have the final VA of less than $3 / 60$ compared with patients having hyphema. Our study also showed similar results that eyes with hyphema were not prone to achieve a good final VA of 20/200 or better $(p=0.000)$.

Lens injury, caused by direct lesion or the development of cataract, was also an important factor of the final VA [32]. In our study, 72 (64.29\%) eyes had final VA of less than 20/200 if lens injury was present $(p=0.000)$. However, Tök et al. [15] found that lens injury had no effect on the final VA because of its association with zone 1, the possibility of performing lens surgery quickly after injury, and improvements in cataract surgery and lens technology.

Endophthalmitis has been mentioned as a prognostic indicator by Williams et al. [33]. Endophthalmitis is associated with special spectrum of organisms such as Bacillus and Staphylococcus and Streptococcus species [34]. In our study, endophthalmitis developed in 36 (11.0\%) eyes. Among them, $29(80.56 \%)$ eyes had poor final VA of less than 20/200, and $7(19.44 \%)$ eyes had good final VA of $20 / 200$ or better. The association between endophthalmitis and the final VA in our study was also statistically significant $(p=0.014)$.

Hutton and Fuller [28] found that wounds involving zone 2 or 3 resulted in significantly higher rates of poor final VA than those involving zone 1 in open globe injuries. Similarly, Madhusudhan et al. [26] also found that patients whose wounds involve zone 3 had 20 times the risk of having poor final VA when compared with those whose wounds involve zone 1. This could be explained by the fact that posterior wounds could cause irreparable damage to photoreceptors such as retina and optic nerve; despite anatomic correction, final VA might remain limited [35]. By multivariate analysis in our study, zone of injury was a significant predictor influencing the final VA $(p=0.000)$. 
OTS study [25] stated that a patient with OTS category one will have a higher risk of poorer final VA as against a patient with OTS category five who will have a higher probability of better final VA. In our study, we found that only $16.98 \%$ of patients with OTS category one had final VA of $20 / 200$ or better, whereas $30.19 \%$ of patients with OTS category one had final VA of NLP. Of the patients with OTS category five, $100 \%$ had final VA of 20/40 or better. Another study by Man and Steel [35] also suggested that OTS possibly had predictive value of the final VA in open globe injury. OTS is of great importance for patients and ophthalmologists.

Several limitations of our study should be acknowledged and discussed. First, as a hospital-based study, we identified a small part of all open globe injuries in Tianjin, and a nationwide eye injury surveillance system should be established. Second, it was related to insufficient medical records such as lids and adnexal injury, extent of injury, and zone involvement intraoperatively, but those data could not be included in the statistical analyses. Third, whether delayed presentation or high risk mechanism injury is related to infection rate and ultimately visual outcome or not was not analyzed. Despite those limitations, we still identified several parameters as potential predictive factors.

In conclusion, prognostic factors for the final VA included initial VA, RAPD, vitreous hemorrhage, lens injury, endophthalmitis, hyphema, retinal detachment, and the zone of injury. However, initial VA, RAPD, and the zone of injury, as independent risk factors, were the most important recommendation for further consideration. OTS, a very comprehensive score to predict final VA in patients with open globe injuries, should be more commonly used by ophthalmologists of the world.

\section{Conflict of Interests}

The authors declare that there is no conflict of interests regarding the publication of this paper.

\section{Acknowledgments}

This study was supported by Natural Science Foundation of Tianjin grant (Grant nos. 12JCYBJC33900 and 14JCYBJC28000) and National Natural Science Foundation of China (Grant nos. 81371038 and 91442124).

\section{References}

[1] D. J. Pieramici, P. Sternberg Jr., T. M. Aaberg Sr. et al., "A system for classifying mechanical injuries of the eye (globe)," American Journal of Ophthalmology, vol. 123, no. 6, pp. 820-831, 1997.

[2] A.-D. Négrel and B. Thylefors, "The global impact of eye injuries," Ophthalmic Epidemiology, vol. 5, no. 3, pp. 143-169, 1998.

[3] M. D. Al-Bdour and M. A. Azab, "Childhood eye injuries in North Jordan," International Ophthalmology, vol. 22, no. 5, pp. 269-273, 1998.

[4] S. de Bustros, R. G. Michels, and B. M. Glaser, "Evolving concepts in the management of posterior segment penetrating ocular injuries," Retina, vol. 10, supplement 1, pp. S72-S75, 1990.
[5] T. Y. Wong, B. E. K. Klein, and R. Klein, "The prevalence and 5-year incidence of ocular trauma. The Beaver Dam Eye study," Ophthalmology, vol. 107, no. 12, pp. 2196-2202, 2000.

[6] A. M. Bauza, P. Emami, N. Soni et al., "A 10-year review of assault-related open-globe injuries at an urban hospital," Graefe's Archive for Clinical and Experimental Ophthalmology, vol. 251, no. 3, pp. 653-659, 2013.

[7] E. De Juan Jr., P. Sternberg Jr., and R. G. Michels, "Penetrating ocular injuries. Types of injuries and visual results," Ophthalmology, vol. 90, no. 11, pp. 1318-1322, 1983.

[8] A. Sudhalkar, J. Chhablani, S. Jalali, and R. Narayanan, “Traumatic vitreous hemorrhage in children-clinical features and outcomes," Eye Science, vol. 29, no. 2, pp. 63-69, 2014.

[9] L. Zhu, Z. Wu, F. Dong et al., "Two kinds of ocular trauma score for paediatric traumatic cataract in penetrating eye injuries," Injury, vol. 46, no. 9, pp. 1828-1833, 2015.

[10] D. Spiegel, J. Nasemann, J. Nawrocki, and V.-P. Gabel, “Severe ocular trauma managed with primary pars plana vitrectomy and silicone oil," Retina, vol. 17, no. 4, pp. 275-285, 1997.

[11] O. Cekic and C. Batman, "Severe ocular trauma managed with primary pars plana vitrectomy and silicone oil," Retina, vol. 18, no. 3, pp. 287-288, 1998.

[12] X. Liu, Z. Liu, Y. Liu et al., "Determination of visual prognosis in children with open globe injuries," Eye, vol. 28, no. 7, pp. 852856, 2014.

[13] S. M. Teixeira, R. R. Bastos, M. S. Falcão, F. M. Falcão-Reis, and A. A. Rocha-Sousa, "Open-globe injuries at an emergency department in porto, Portugal: clinical features and prognostic factors," European Journal of Ophthalmology, vol. 24, no. 6, pp. 932-939, 2014.

[14] R. Agrawal, H. S. Wei, and S. Teoh, "Prognostic factors for open globe injuries and correlation of ocular trauma score at a tertiary referral eye care centre in Singapore," Indian Journal of Ophthalmology, vol. 61, no. 9, pp. 502-506, 2013.

[15] O. Y. Tök, L. Tok, E. Eraslan, D. Ozkaya, F. Ornek, and Y. Bardak, "Prognostic factors influencing final visual acuity in open globe injuries," Journal of Trauma-Injury, Infection and Critical Care, vol. 71, no. 6, pp. 1794-1800, 2011.

[16] B. Esmaeli, S. G. Elner, M. A. Schork, and V. M. Elner, "Visual outcome and ocular survival after penetrating trauma: a clinicopathologic study," Ophthalmology, vol. 102, no. 3, pp. 393-400, 1995.

[17] C. M. Gilbert, H. K. Soong, and L. W. Hirst, "A two-year prospective study of penetrating ocular trauma at the Wilmer Ophthalmological Institute," Annals of Ophthalmology, vol. 19, no. 3, pp. 104-106, 1987.

[18] D. J. Pieramici, M. W. MacCumber, M. U. Humayun, M. J. Marsh, and E. J. De Juan, "Open-globe injury. Update on types of injuries and visual results," Ophthalmology, vol. 103, no. 11, pp. 1798-1803, 1996.

[19] D. J. Pieramici, K.-G. A. Eong, P. Sternberg Jr., and M. J. Marsh, "The prognostic significance of a system for classifying mechanical injuries of the eye (globe) in open-globe injuries," Journal of Trauma-Injury Infection \& Critical Care, vol. 54, no. 4, pp. 750-754, 2003.

[20] P. Sternberg Jr., E. de Juan Jr., R. G. Michels, and C. Auer, "Multivariate analysis of prognostic factors in penetrating ocular injuries," American Journal of Ophthalmology, vol. 98, no. 4, pp. 467-472, 1984.

[21] I. Rahman, A. Maino, D. Devadason, and B. Leatherbarrow, "Open globe injuries: factors predictive of poor outcome," Eye, vol. 20, no. 12, pp. 1336-1341, 2006. 
[22] G. W. Schmidt, A. T. Broman, H. B. Hindman, and M. P. Grant, "Vision survival after open globe injury predicted by classification and regression tree analysis," Ophthalmology, vol. 115, no. 1, pp. 202-209, 2008.

[23] S. B. Han and H. G. Yu, "Visual outcome after open globe injury and its predictive factors in Korea," Journal of Trauma: Injury, Infection and Critical Care, vol. 69, no. 5, pp. E66-E72, 2010.

[24] R. Agrawal, G. Rao, R. Naigaonkar, X. Ou, and S. Desai, "Prognostic factors for vision outcome after surgical repair of open globe injuries," Indian Journal of Ophthalmology, vol. 59, no. 6, pp. 465-470, 2011.

[25] F. Kuhn, R. Maisiak, L. Mann, V. Mester, R. Morris, and C. D. Witherspoon, “The ocular trauma score (OTS)," Ophthalmology Clinics of North America, vol. 15, no. 2, pp. 163-165, 2002.

[26] P. Madhusudhan, L. M. Evelyn-Tai, N. Zamri, H. Adil, and W. H. Wan-Hazabbah, "Open globe injury in Hospital Universiti Sains Malaysia-a 10-year review," International Journal of Ophthalmology, vol. 7, no. 3, pp. 486-490, 2014.

[27] C. A. Cheung, M. Rogers-Martel, L. Golas, A. Chepurny, J. B. Martel, and J. R. Martel, "Hospital-based ocular emergencies: epidemiology, treatment, and visual outcomes," The American Journal of Emergency Medicine, vol. 32, no. 3, pp. 221-224, 2014.

[28] W. L. Hutton and D. G. Fuller, "Factors influencing final visual results in severely injured eyes," American Journal of Ophthalmology, vol. 97, no. 6, pp. 715-722, 1984.

[29] W. S. Thompson, P. E. Rubsamen, H. W. Flynn Jr., J. Schiffman, and S. W. Cousins, "Endophthalmitis after penetrating trauma: risk factors and visual acuity outcomes," Ophthalmology, vol. 102, no. 11, pp. 1696-1701, 1995.

[30] K. Rostomian, A. B. Thach, A. Isfahani, A. Pakkar, R. Pakkar, and M. Borchert, "Open globe injuries in children," Journal of AAPOS, vol. 2, no. 4, pp. 234-238, 1998.

[31] C.-H. Lee, L. Lee, L.-Y. Kao, K.-K. Lin, and M.-L. Yang, "Prognostic indicators of open globe injuries in children," American Journal of Emergency Medicine, vol. 27, no. 5, pp. 530-535, 2009.

[32] C. C. Barr, "Prognostic factors in corneoscleral lacerations," Archives of Ophthalmology, vol. 101, no. 6, pp. 919-924, 1983.

[33] D. F. Williams, W. F. Mieler, G. W. Abrams, and H. Lewis, "Results and prognostic factors in penetrating ocular injuries with retained intraocular foreign bodies," Ophthalmology, vol. 95, no. 7, pp. 911-916, 1988.

[34] G. Gokce, G. Sobaci, and C. Ozgonul, "Post-traumatic endophthalmitis: a mini-review," Seminars in Ophthalmology, 2014.

[35] C. Y. W. Man and D. Steel, "Visual outcome after open globe injury: a comparison of two prognostic models-the Ocular Trauma Score and the Classification and Regression Tree," Eye, vol. 24, no. 1, pp. 84-89, 2010. 


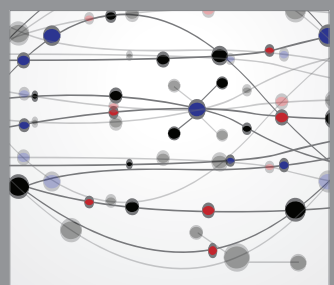

The Scientific World Journal
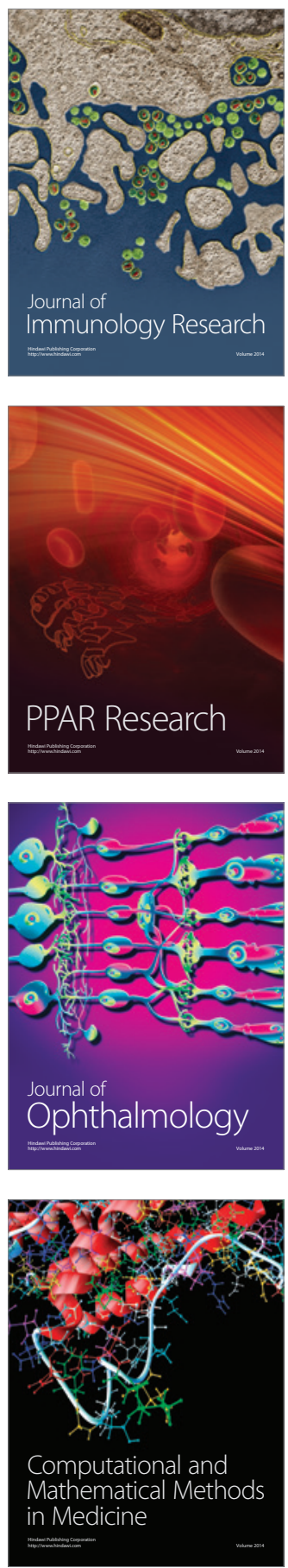

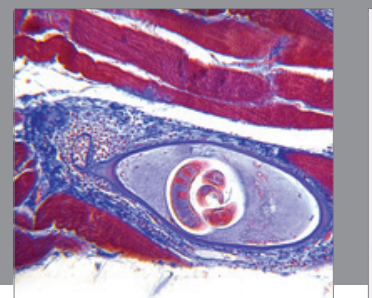

Gastroenterology

Research and Practice
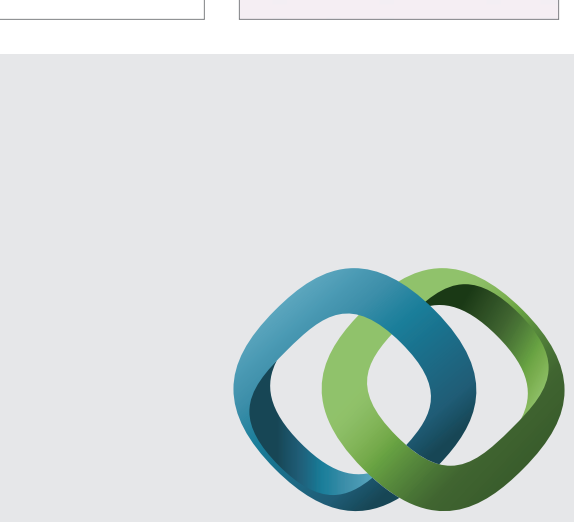

\section{Hindawi}

Submit your manuscripts at

http://www.hindawi.com
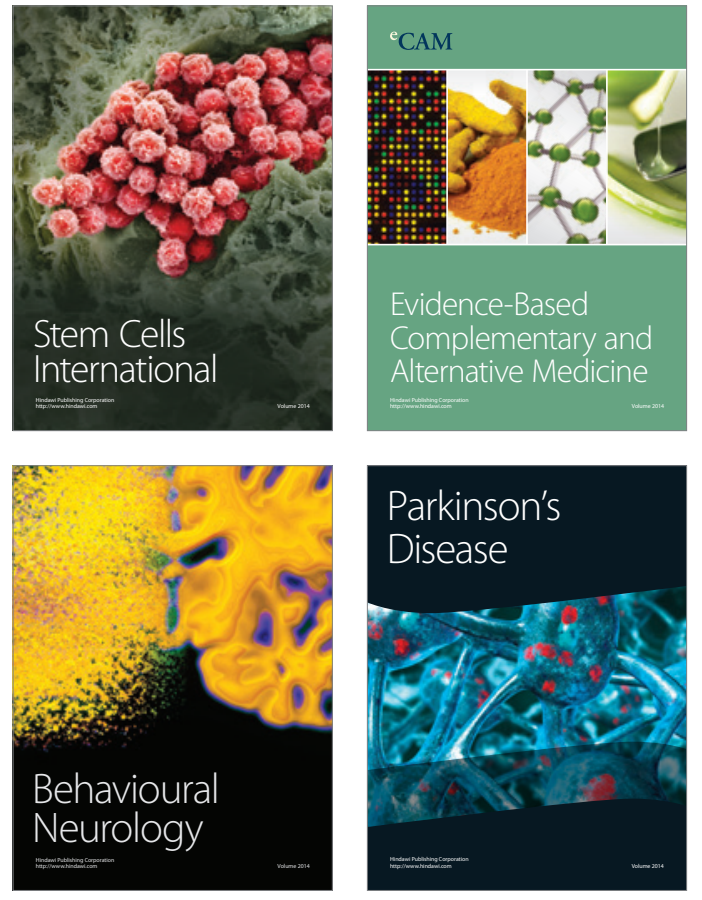
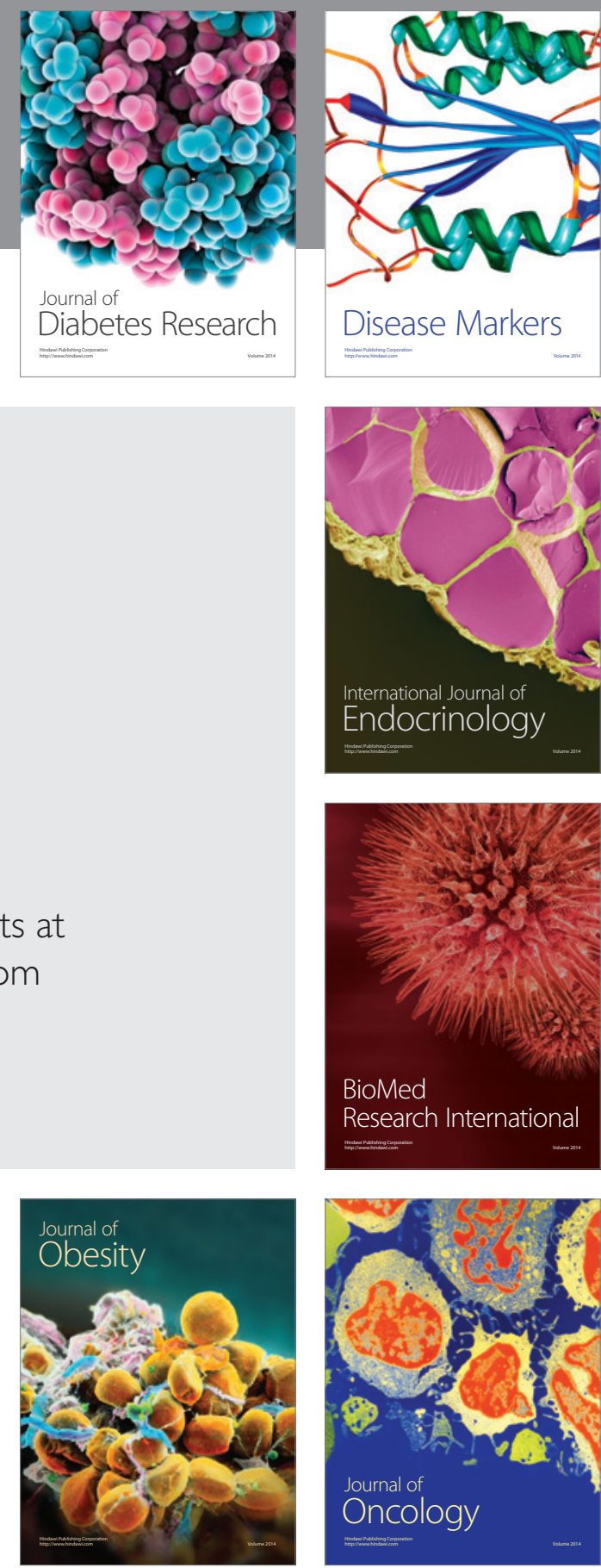

Disease Markers
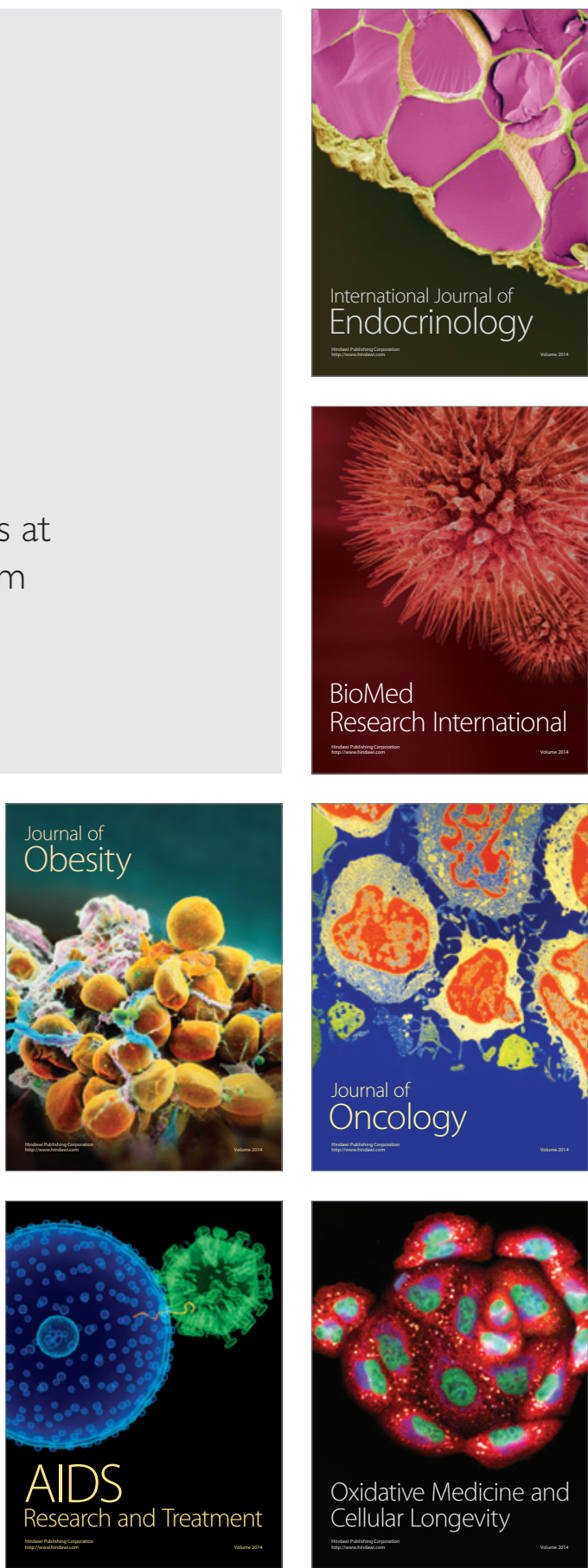